\title{
PLANNING FOR THE FORESTRY SECTOR OF SRI LANKA
}

\author{
S Medawewa and M A Kumaradasa \\ FDD, Ministry of Forestry and Environment
}

Forest sector planning depends on a general framework to help define and implement forest conservation and sustainable management. The framework must strive to balance environmental and economic objectives, promote social and cultural functions of forests, and define the level of participation of the public and private sector. At all levels of planning related to forests, the guiding question should be; forests for whom and for what? Hence planning must be designed to promote a wide and open dialogue on this question.

The focus on planning at present is based on sustainable forest management for multiple benefits. This shift marks a significant change from production and management techniques designed to ensure a sustained commodity flow over time, to one that ensures to socio-economic, environmental and ecological benefit flows, while maintaining the potential to respond to evolving demands.

Forestry sector planning is the process of seeking, through time and space, the best translation of national policy statements into goals and means in order to implement the objectives of the policy. In line with this concept the National Forestry Policy of 1995 (NFP) was formulated as a basis for planning for the forestry sector of this country.

In developing countries, most pressures on forests originate outside forestry. National fiscal, monetary, trade, pricing and investment policies directly and indirectly affect the demand for land and forests. At the same time, policies and programmes in forestry are expected to support higher national goals. Identifying mechanisms to plan within multisectoral and macroeconomic perspectives is a large part of the planning challenge facing forestry. Planning has to be conceived as a participatory activity in which "ownership" of the process and result is widely shared by all stakeholders.

The development of the Forestry Sector Master Plan (FSMP) was based on the NFP, and hence they are complementary. The FSMP is a long term development framework, which when implemented will ensure that our forests and other biodiversity resources, will be conserved, and that forests can provide environmental services and forestry products to meet the needs of the people sustainably. Based on the programme components recommended in the FSMP, a Five-Year Implementation Programme (FYIP) was prepared as a preparatory programme for the full-scale implementation of the NFP and the FSMP.

The FYIP stresses the importance of conservation, and provides a new direction to the forestry sector of this country; a major role for the people and the non-state sector in forestry development activities and efficient management of forest resources.

Keeping in line with the participatory concept, the approach followed in the planning process was a collaborative exercise where all stakeholders were able to take part. For the FYIP the stakeholders were able to directly contribute to developing the programme components. The success of the FYIP can only be judged once implemented. The success of planning can be judged by the extent to which plans are accepted by society, and the competing interest in it, and the degree to which planning actually guides decision making and resource allocation.

Proceedings of the Third Annual Forestry Symposium 1997, of the Department of Forestry and Environmental Science, University of Sri Jayewardenepura, Sri Lanka 